\title{
Retraction: The Carboxy-terminus of BAK1 regulates kinase activity and is required for normal growth of Arabidopsis
}

\author{
Frontiers Editorial Office * \\ A retraction of the Original Research Article
}

The Carboxy-terminus of BAK1 regulates kinase activity and is required for normal growth of Arabidopsis

by Oh, M.-H., Wang, X., Kim, S. Y., Wu, X., Clouse, S. D., and Huber, S. C. (2014). Front. Plant Sci. 5:16. doi: 10.3389/fpls.2014.00016

The Journal and Authors retract the 4 February 2014 article cited above for the following reasons provided by the Authors:

After publication of this article, we became aware that the transgenic plants described in this manuscript were not correct because of inadvertent errors in genotyping of the parent plants, and thus the results presented in Figures 4, 6 are not valid. We realized from the immunoblot result presented in Figure 4B, that immunoprecipitated BAK1- $\Delta$ CT-Flag had the same apparent molecular weight as did BAK1-Flag, despite the fact that truncated protein should have been $\sim 4$ $\mathrm{kDa}$ smaller but that size difference was not apparent. We subsequently confirmed that the BAK1 construct used was not truncated but was full length. At the moment we cannot explain why the transgenic plants show reduced growth, but it is clear that it is not related to the BAK1 transgene.

\section{OPEN ACCESS}

Approved by:

Joshua L. Heazlewood,

The University of Melbourne, Australia

${ }^{*}$ Correspondence:

Frontiers Editorial Office editorial.office@frontiersin.org

Specialty section:

This article was submitted to

Plant Physiology,

a section of the journal

Frontiers in Plant Science

Received: 15 June 2016

Accepted: 15 June 2016

Published: 24 June 2016

Citation:

Frontiers Editorial Office (2016) Retraction: The Carboxy-terminus of $B A K 1$ regulates kinase activity and is required for normal growth of Arabidopsis. Front. Plant Sci. 7:960 doi: $10.3389 /$ fpls.2016.00960
However, the results presented in Figures 1-3, 5 with recombinant proteins in vitro are valid, and thus conclusions drawn from functional and interaction studies in vitro are correct. Regrettably, the relevance to the function of BAK1 in vivo remains uncertain and it is no longer clear whether the carboxy-terminus of BAK1 is "required for normal growth of Arabidopsis" as stated in the title. The responsibility for this experimental error rests with only two of the authors: the senior author (MHO) who was a Senior Research Scientist when these studies were conducted with extensive experience in molecular biology and whose primary responsibility was production of the transgenic plants. The other responsible individual was the corresponding author $(\mathrm{SCH})$, who failed to provide adequate oversight to the production of the transgenic plants and as a result, critical checks and balances were not in place. The other authors (WX, SYK, XW, and SDC) are not responsible in any way for this regrettable situation. We are pursuing follow-up experiments to correctly generate the BAK1- $\triangle$ CT-Flag transgenic plants in the bak1 bkk1 double null background that are required to test the functional role in vivo and hope to publish soon.

We sincerely regret any scientific misconceptions that have been caused by the above paper; the corresponding author's laboratory wasted an additional year studying these plants before the error was discovered. We apologize to the entire scientific community for the misinformation and any adverse consequences that may have resulted.

Copyright () 2016 Frontiers Editorial Office. This is an open-access article distributed under the terms of the Creative Commons Attribution License (CC BY). The use, distribution or reproduction in other forums is permitted, provided the original author(s) or licensor are credited and that the original publication in this journal is cited, in accordance with accepted academic practice. No use, distribution or reproduction is permitted which does not comply with these terms. 